\title{
Uma possibilidade para prática do Ecoturismo: um breve diagnóstico na Comunidade dos Pilões em Miracema (TO)
}

\section{A possibility for the practice of Ecotourism: a brief diagnosis in the Community of Pilões in Miracema (TO, Brazil)}

\author{
João Paulo Carneiro dos Reis, Rosane Balsan, Sandra de Oliveira Gomes Pereira
}

\begin{abstract}
RESUMO: O presente artigo tem o objetivo diagnosticar as possibilidades da prática do ecoturismo na comunidade rural dos Pilões, em Miracema do Tocantins. A pesquisa bibliográfica, empírica e ação participante. No primeiro momento, discute a importância do ecoturismo e do turismo, propondo uma reflexão acerca dessas práticas, pensandoas enquanto ações sustentáveis e que trarão benefícios à comunidade local. A partir do segundo momento, foram apresentados os resultados da experiência de uma visitação à Serra do Bandeira, situada na comunidade dos Pilões, zona rural do município de Miracema do Tocantins. Na ocasião, um grupo formado por onze pessoas, dentre elas moradores, professores e representante do Instituto de Desenvolvimento Rural do Tocantins (Ruraltins), realizaram uma trilha de cinco quilômetros, em julho de 2017, com o propósito de observar e analisar o potencial turístico natural da região dos Pilões. 0 resultado inicial dessa ação foi a produção de uma matéria jornalística onde se destacaram as potencialidades e as dificuldades da região e, em outubro de 2017, fundada a Associação Agroturística da região dos Pilões e Ilha da Ema (Agrotur). Um espaço que garante à comunidade local discutir e propor ações para as dificuldades enfrentadas na região e lutar coletivamente por melhorias.
\end{abstract}

PALAVRAS CHAVE: Ecoturismo; Expedição; Potencial Turístico.

ABSTRACT: This article aims to verify the possibilities of ecotourism practice in the rural community of Pilões, in Miracema do Tocantins. The research bibliographic, empirical and participant action. At first, it discussed the importance of ecotourism and tourism, proposing a reflection on these practices, thinking of them as sustainable actions that will bring benefits to the local community. From the second moment, the results of a visit to Serra do Bandeira, located in the community of Pilões, rural area of Miracema do Tocantins, were presented. On that occasion, a group of eleven people, including residents, teachers and a representative of the Rural Development Institute of Tocantins (Ruraltins), undertook a five-kilometer trail in July 2017, with the purpose of observing and analyzing the natural tourism potential of the Pilões region. The initial result of this action was the production of a journalistic article that highlighted the region's potential the difficulties, and in October 2017, founded the Agro-Tourism Association of the Pilões Region and Emma Island (Agrotur). A space that guarantees the local community to discuss and propose actions for the difficulties faced in the region and fight collectively for improvements.

KEYWORDS: Ecotourism; Expedition; Touristic Potential. 


\section{Introdução}

Este artigo vem ao encontro a uma temática, em que é na atualidade discutida por diferentes campos científicos, a questão ambiental. A prática do ecoturismo, a qual vem sendo debatida no meio acadêmico, busca tratar a questão sobre a observação da fauna e flora, nos diferentes biomas presentes no país. Tendo em vista que em decorrência do desmatamento e da extinção de espécies de plantas e animais é de relevância discutir e pensar, na atualidade, em formas de preservação dos espaços conservados em diferentes escalas no Brasil.

Esta ação ocorreu por meio de uma visitação, em 09 de julho de 2017, à Serra do Bandeira, situada na comunidade dos Pilões, na zona rural do município de Miracema do Tocantins. Participaram da expedição, moradores da comunidade, duas pessoas representando o órgão estadual de apoio ao desenvolvimento rural do Estado do Tocantins - RURALTINS, e um jornalista. Na ocasião foi feito um levantamento dos pontos turísticos e as dificuldades locais na comunidade dos Pilões.

Foi utilizada a pesquisa ação, onde o pesquisador faz parte do grupo social que se deseja estudar. Neste sentido, teve inicialmente finalidade principal diagnosticar o potencial turístico na comunidade dos Pilões. Os objetivos específicos foram: descrever com base na observação o percurso da trilha realizada, identificar os elementos capazes de promover o turismo na comunidade e apresentar algumas ações desenvolvidas no momento após visitação já desenvolvida na região.

No primeiro momento deste estudo, a partir da pesquisa bibliográfica, trata brevemente acerca da prática ecoturística no Brasil, sobre seu surgimento e as políticas existentes a respeito da temática, além da abordagem, ainda de forma breve, sobre planejamento turístico de maneira coletiva.

O segundo instante da pesquisa apresenta uma descrição por meio da observação ocorrida na visitação a Serra do Bandeira na região dos Pilões no município de Miracema do Tocantins. Enquanto pesquisador participante, após a expedição foi o momento de descrever e fazer um breve levantamento dos atrativos naturais existentes na comunidade, juntamente com os demais participantes. E o resultado desta ação se concretizou em uma matéria jornalista, socializada aqui neste estudo. E partir então do reconhecimento dos atrativos e do material produzido, ação posterior foi à fundação da associação AGROTUR- Associação Agroturística dos Pilões e llha da Ema, fundada em outubro de 2017 e atuante até o presente momento.

Ela surge da necessidade da comunidade local em ter forças para buscar novas parcerias e também cobrar ações mais concretas do poder público para a região, que se localiza a 43 quilômetros da sede do município de Miracema do Tocantins. Sobre a pesquisa ação, a qual o pesquisador está envolvido no processo, Thiolent (2004), utiliza o termo metodologia da pesquisa ação, definindo-a como sendo um tipo de pesquisa social com base empírica que é concebida e realizada em estreita associação com uma ação ou com a resolução de um problema coletivo e no qual os pesquisadores e os participantes representativos da situação ou do problema estão envolvidos de modo cooperativo ou participativo.

Sobre pesquisa ação, Fonseca (2002, p.35), assim a define: 
Pesquisa ação é um processo de longa duração, desenvolvido em colaboração com grupos reais inseridos no seu contexto, sendo a sua finalidade, objetivos e as orientações discutidas e negociadas entre o objeto de pesquisa e o pesquisador em função de uma situação ou prática social concreta (FONSECA, 2002, p.36).

O autor complementa que "é uma situação social situada em conjunto e não um conjunto de variáveis isoladas que se poderiam analisar independentemente do resto". Ou seja, interessam-se nessa pesquisa os elementos que produzem mudança social, muito mais do que os dados coletados em seu decurso, por isso a atitude participativa do pesquisador é essencial.

Assim, neste estudo a pesquisa ação foi desenvolvida mediante a organização expedição em 9 de julho de 2017, idealizada por Cristóvão Alves Feitosa e João Paulo Carneiro dos Reis. De maneira informal, buscou sensibilizar outros moradores sobre a possibilidade do turismo naquele lugar. $E$ assim, na respectiva data, foram convidados mais sete moradores da região.

Formou-se, então, um grupo composto por 11 pessoas, sendo oito delas moradores do local, dois representantes da RURALTINS, e também a presença de um jornalista convidado, o qual posteriormente produziu uma matéria a respeito da expedição ${ }^{1}$.

Organizou-se a trilha e na manhã do dia 09 acorreu a expedição a Serra do Bandeira, localizada em propriedades rurais no município, sendo que os proprietários sinalizaram a intenção e anseio de receber pessoas para conhecerem o local e desenvolvê-lo como ponto turístico. No segundo instante, foram descritos os aspectos empíricos visíveis, os quais resultaram em um levantamento do potencial turístico do local visitado.

Sobre o local visitado, é situado dentro de várias propriedades nesta comunidade dos Pilões que fica a 43 quilômetros da sede do município de Miracema- TO'1.

\section{A prática do ecoturismo e o desenvolvimento do turismo}

O ecoturismo surgiu com o movimento ambiental global no final de 1970, uma resposta às preocupações com o desenvolvimento econômico, à degradação do meio ambiente e as questões sociais provocadas pelo turismo em massa. Compreendido, inicialmente, enquanto uma pratica de visitas às áreas naturais que se encontram relativamente sem distúrbios ou contaminação, com o objetivo específico de estudar, admirar e desfrutar a paisagem, flora, fauna e qualquer manifestação cultural (passada ou presente) que ocorra nestas áreas (BUENO, 2006; PIRES, 1998).

No Brasil o conceito foi introduzido pelo Instituto Brasileiro do Turismo EMBRATUR, que iniciou em 1985 o Projeto Turismo Ecológico, resultando, dois anos depois, na Comissão Técnica Nacional, a primeira iniciativa com intenção de regular o segmento. Este tipo de turismo ganhou visibilidade e impulsionou o mercado brasileiro. Já em 1994, com a publicação das Diretrizes para uma Política Nacional de Ecoturismo, o turismo ecológico passou a ser conceituado e denominado como Ecoturismo. 
O ecoturismo pode conduzir à conservação dos recursos naturais e à melhoria da qualidade de vida da população local. Entretanto, de acordo com Ramos e Oliveira (2008).

É preciso que a atividade seja conduzida respeitando as características, fragilidades e limites socioambientais da área determinada e, sobretudo, orientadas por ações efetivas de educação ambiental, pois caso estas ações não estejam presentes e a visitação ao espaço natural não for comprometida com uma transformação do indivíduo e da relação deste com o meio, seria melhor não estimular tais visitas, poupando o ambiente de possíveis impactos negativos (RAMOS; OLIVEIRA, 2008, p.20 apud BICCHI; NEIMAN, 2017: MENDONÇA, 2005).

A Política Nacional de Educação Ambiental (PNEA) foi instituída em 1999 e considera a educação ambiental como um direito garantido à sociedade, mencionando que o ecoturismo deve ser incentivado como uma das formas de educação ambiental não-formal que, segundo o PNEA, são definidas como ações e práticas educativas voltadas à sensibilização da coletividade sobre as questões ambientais e à sua organização e participação na defesa da qualidade do meio ambiente (BRASIL, 2005). A PNE estabeleceu os seguintes princípios, que reforçam a importância desta política para o cenário nacional:

Leis que permita a integralmente às atividades ecoturística: Concepção de ambiente em sua totalidade, considerando a interdependência sistêmica entre o meio natural e o construído, o socioeconômico e o cultural, o físico e o espiritual, sob enfoque da sustentabilidade; Abordagem articulada das questões ambientais locais, regionais, nacionais, transfronteiriças e globais Reconhecimento da diversidade cultural, étnica, racial, genética, de espécies e de ecossistemas; Democratização na produção e divulgação de conhecimento e fomento à interatividade na informação (BRASIL, 2005 p.20).

Para Rabelo (2010), viver experiências é ampliar as possibilidades de educação, porém, a concepção de educação é quase sempre associada somente à aquisição de conhecimentos científicos e aos espaços formais, como escolas e universidades. Elabora-se o currículo e este define, dentre outros elementos, quais os conteúdos a serem adquiridos, como se dará a avaliação, que competências e habilidades se esperam que os alunos desenvolvam ao obter tal conhecimento. Ainda de acordo com Rabelo (2010, p.20), "o ecoturismo é um espaço/tempo de formação que pode contribuir para a vivência de experiências que serão traduzidas pela racionalidade estética - expressiva e moral - prática, proporcionando um novo nascimento."

Nesse sentido, para Novelli (2001) e Rabelo (2010), a educação proporciona o segundo nascimento do indivíduo porque o torna o autônomo, senhor de si no convívio de seu povo. O mesmo não acontece no âmbito da natureza, reduzida em si mesma, ou seja, enclausurada numa existência determinada. Compreende-se, portanto, que a atual importância do ecoturismo na sociedade não está apenas 
baseada na variável econômica, mas principalmente em seu potencial educativo e de conservação da natureza, advindos das experiências e sensações vivenciadas em meio à natureza.

O caráter educativo do ecoturismo baseia-se no fato de que esta atividade, comprometida com a conservação da natureza, prevê o seu desenvolvimento a partir da participação responsável dos 'ecoturistas' em ambientes de elevada importância tanto para essa atividade quanto para a humanidade (BUENO, 2006).

A cada ano a possibilidade do ecoturismo no Brasil se expande por meio das descobertas de novos locais para a apreciação dessa prática. Assim, convém destacar que tanto o turismo convencional quanto o ecoturismo podem se configurar como atividades empresariais que estimulam o consumismo, ocasionando á transformação de lugares em não-lugares, o que não permite viver qualquer experiência. Em ambos os casos, turismo e ecoturismo, a frustração poderá ser a mesma que se verifica ao comprar qualquer outro bem material que só oferece a possibilidade de prazer no momento de sua aquisição. No ecoturismo, inclusive, há uma incoerência total com a sua própria finalidade de turismo alternativo (RABELO, 2010).

Neste estudo, pauta-se também no entendimento básico de como os agentes responsável, comunidades, agentes públicos e privados para promoção do turismo em dado local. Precisa saber e ter como articulação e desenvolva de maneira coletiva, é necessário que haja primeiro o diálogo, então se chegue ao planejamento turístico e de fato se chegue à possibilidade da prática do ecoturística saudável e sustentável.

Sobre a prática do turismo, parte das relações entre os vários subsistemas do turismo, dando ênfase ao caráter holístico da atividade e suas inter-relações com o meio. Assim, o turismo é o estudo do homem longe de seu local de residência, da indústria que satisfaz suas necessidades, e dos impactos que ambos, ele e a indústria, geram sobre os ambientes físicos, econômicos e socioculturais da área receptora (BENI,1998).

Pois para discutir o turismo atualmente, é necessária a compreensão das teorias relacionadas a diversas áreas do conhecimento, sendo objeto de estudo da economia, história, geografia, sociologia e, em especial, do próprio turismo. Sendo assim, fundamental para a construção do conhecimento no campo de estudo sobre essa prática, caráter que evidencia a transdisciplinaridade do turismo (BINFARÉ, et al., 2016)

Nesta perspectiva, o turismo do século XXI não permite mais improvisações ou esquemas amadorísticos. Há necessidade de profissionalismo e planejamento face às novas exigências da demanda. Esse imperativo é justificável, sobretudo no contexto das diversas análises sobre as consequências do desenvolvimento do turismo nas localidades receptoras (BINFARÉ, et al., 2016).

O turismo é essencialmente movimento de pessoas e atendimento às suas necessidades, assim como às necessidades das outras pessoas que viajam. Sendo então, o turismo um fenômeno de interação entre o turista e o núcleo receptor e de todas as atividades decorrentes dessa interação. Essas relações permitem que o indivíduo se distancie de seu cotidiano (BINFARÉ et al., 2016).

Diante as respectivas prerrogativas, a preocupação neste estudo vai além de divulgar e mostrar a possibilidade do ecoturismo na Serra do Bandeira, em 
Miracema- TO, para a comunidade geral que tem o interesse em visitá-la. É também de retratar as ações feitas a partir da visitação de 09 de julho 2017 até momento atual. O qual, a comunidade está se organizando, e buscando assim, apoios e diálogos com outras instituições em busca de parcerias e que promova a prática ecoturística na região de forma planejada.

Mas, para que essa prática do turismo se efetive, compreende-se ser de real importância o planejamento, pois ele é um processo ativo e, conforme Barretto (1991), é uma atividade dinâmica, não é estático, e possui muitos fatores concomitantes e que necessitam serem analisados e coordenados para se alcançar um objetivo possível e satisfatório. É um processo que precisa ser constantemente repensado após o alcance dos objetivos traçados.

\section{Metodologia}

O local onde aconteceu a expedição fica há 43 quilômetros da sede do município, sua extensão, com altitude variando de 300 a 500 metros é formada por 16 propriedades particulares. A seguir, observa-se pontualmente.

\section{0 percurso realizado pela equipe em 09 de julho de 2017 na Serra do Bandeira em Miracema-TO.}

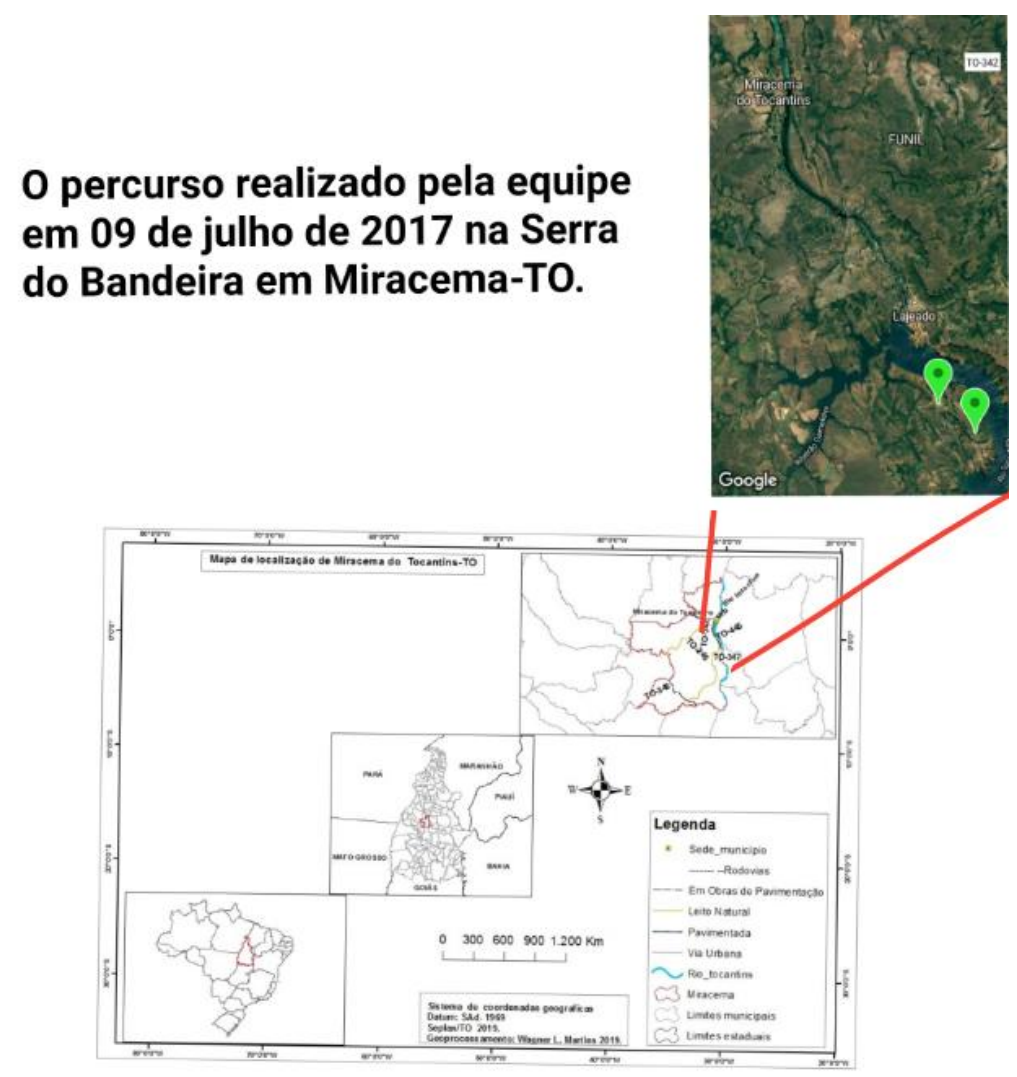

Figura 1: Localização do local da expedição no Município de Miracema do Tocantins/TO. Fonte:Elaboração cartográfica (MARTINS, 2019 editado por REIS, 2019).

Figure 1: Location of the expedition site in the Municipality of Miracema do Tocantins / TO. Source: Cartographic elaboration (MARTINS, 2019 edited by REIS, 2019).

Nesta etapa da pesquisa, são socializados os passos que desencadeou o presente estudo, sendo o resultado de um conjunto de ações voltadas ao desenvolvimento do ecoturismo e do turismo nas propriedades rurais na comunidade 
dos Pilões no município de Miracema/TO, onde, um dos seus atrativos principais é a Serra do Bandeira. Ela pertence a um aglomerado de propriedades particulares, percebe-se que há o interesse de alguns proprietários em divulgar e desenvolver a prática do ecoturismo naquele lugar, devido à existência de pinturas rupestres poucas visitadas, mirantes em altitudes entre 300 a 400 metros e rica fauna e flora ainda existente no local.

A ideia inicial surgiu do morador há mais de sete anos na região, Cristóvão Alves Feitosa, o qual em conversas informais com outros moradores sensibilizou sobre a existência do potencial turístico da região dos Pilões e da região circunvizinha, Ilha da Ema. Socializando com o professor João Paulo Carneiro e com outros moradores, surgiu a ideia de promover uma visitação à Serra do Bandeira, na comunidade dos Pilões. E assim, convidaram dois representantes do RURALTINS, o secretário do turismo do município e um jornalista. Na data marcada, os convidados aceitaram o convite, com exceção do secretário do turismo que não apareceu.

O percurso da expedição estabelecido foi de cinco quilômetros de extensão sobre a Serra visitada, a equipe saiu as 06h30min da manhã do dia 09 de julho de 2017, o qual todos, equipados com alimentos e muita água iniciaram a escalação ao local. Como já colocado, a altitude do local varia entre 300 a 400 metros, somando com o percurso da trilha, totalizaram 10 quilômetros de caminhada. Há pontos que a acessibilidade ainda é difícil, até chegar ao local projetado pela equipe, onde ficam localizadas as pinturas rupestres. A Figura 2 foi registrada no alto da Serra do Bandeira, na metade do percurso trilhado.

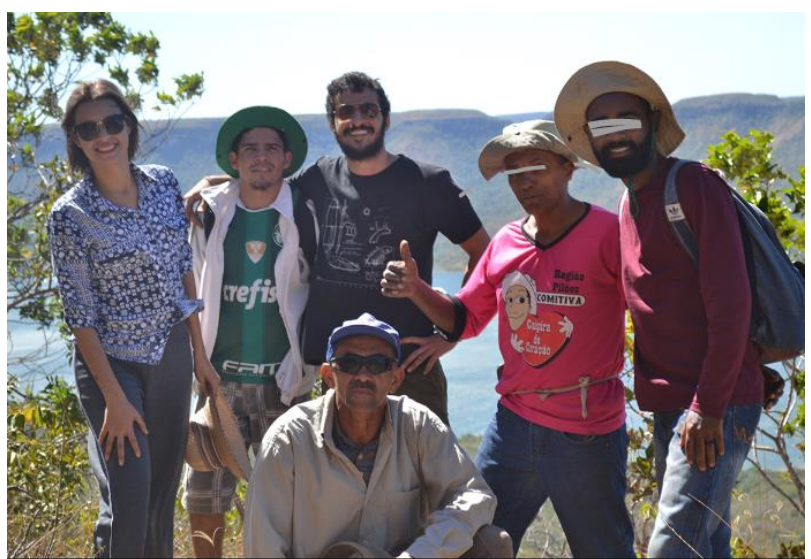

Figura 2: registro no alto da Serra de integrantes da equipe Fonte:(MIRANDA, 2017).

Figure 2: registration at the top of the Serra by team members Source: (MIRANDA, 2017).

Seguindo o percurso, observou-se uma vegetação rasteira e a presença de várias árvores frutíferas do cerrado, como também os vestígios de rastros de animais tipicamente deste bioma. Por último, o local esperado na visita os lajedos, contendo uma série de pinturas rupestres (Figura 3). 


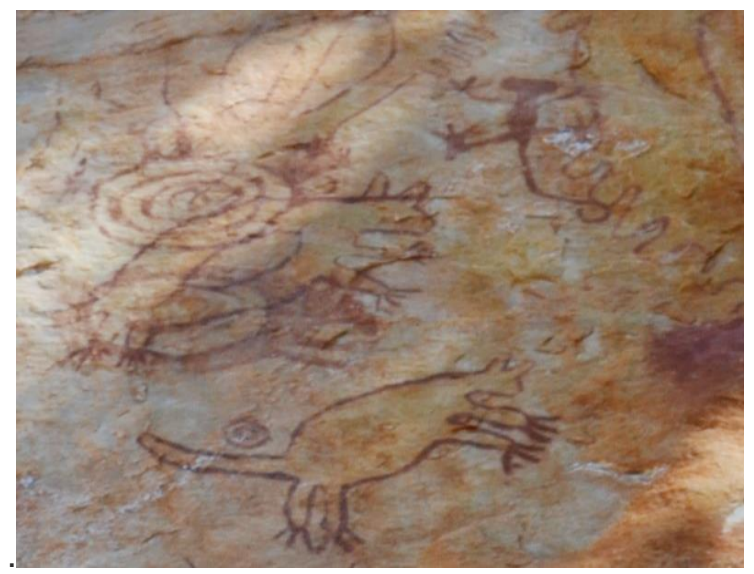

Figura 3: Pinturas rupestres na Serra do Bandeira em Miracema-TO. Fonte: (MIRANDA, 2017).

Figure 3: Rock paintings in Serra do Bandeira in Miracema-TO. Source: (MIRANDA, 2017).

O registro agora mostra o momento do retorno da visita onde existe a descida da Serra do Bandeira, já próximo da residência do seu Manoel Rodrigues (Figura 4). De maneira geral, calcula-se aproximadamente 500 mil metros de trilhas, feita pela equipe neste percurso, o qual saímos às 6:30 da manhã e com ás14:00 horas.

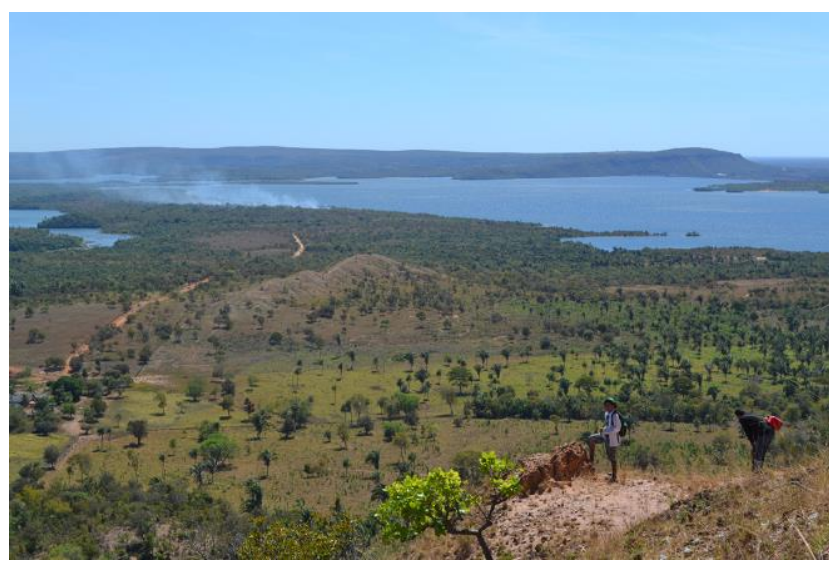

Figura 4: Descida da Serra do Bandeira, Miracema do Tocantins. Fonte: (MIRANDA, 2017).

Figure 4: Descent from Serra do Bandeira, Miracema do Tocantins. Source: (MIRANDA, 2017).

Está outra imagem é registrada logo após todos descerem já na casa do seu Manoel Rodrigues, o qual estava nos aguardando com um almoço.

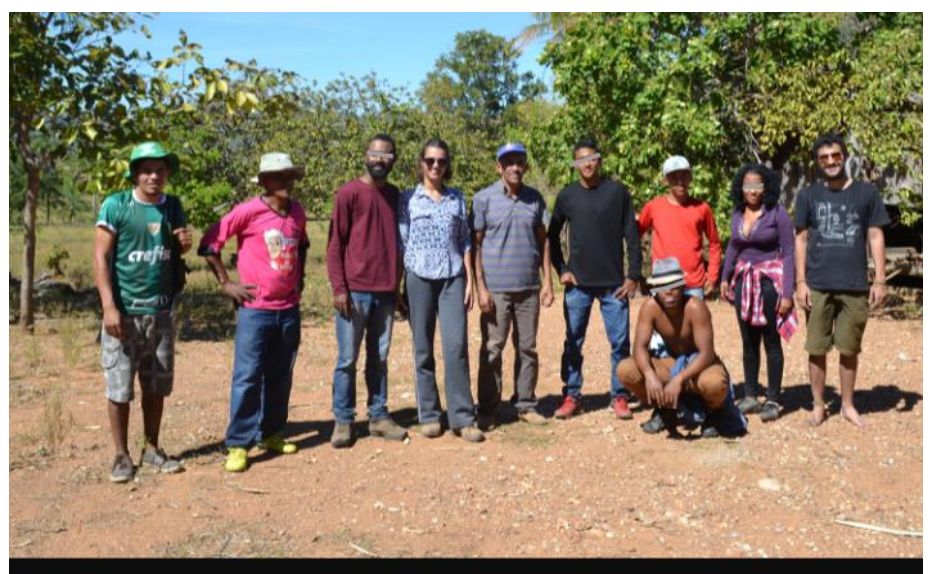

Figura 5: foto da equipe da visitação. Fonte: (SANTOS, 2017). Figure 5: photo of the visitation team. Source: (SANTOS, 2017). 
Após o almoço, o jornalista realizou a entrevista com os presentes. Busca-se aqui tecer algumas considerações referentes à matéria jornalística produzida a partir da experiência vivida na visita ao local, bem como as dificuldades encontradas e a opinião dos moradores e idealizadores da expedição sobre o desejo de desenvolver o turismo na região

A matéria apresenta as dificuldades encontradas durante a visitação, segundo Miranda (2017) o percurso não é fácil e devido à inclinação do terreno, parte do trajeto é feito com o auxílio de cordas para subir e descer. Mas tudo vale a pena, a paisagem é deslumbrante e apresenta uma perspectiva ampla do Rio Tocantins e das serras que rodeiam a região. No local, existem diversos animais representados, alguns são de fácil identificação, como peixes, tartarugas, lagartos, tatus e porcos. Já outros, pela sobreposição de algumas figuras, ficam difíceis de decifrar.

O local visitado é descrito, sendo a Serra uma das mais elevadas e altas da região. No topo observa-se a presença de rochas metamórficas que são os mais recentes vestígios arqueológicos. E há muitos sedimentos, fragmentos de rochas ao longo do caminho e são preservadas o que demonstra que o local não passou por sérias mudanças (MIRANDA, 2017). Ressaltam também os aspectos físicos e naturais, observados durante o percurso na Serra do Bandeira, baseado nas informações concedidas por meio da entrevista realizada com integrante da equipe, morador e professor de uma escola na região, o professor de Geografia João Paulo Carneiro.

$\mathrm{Na}$ referida matéria, foram apresentados maiores detalhes do local, conforme informações obtidas através da entrevista. O professor afirma que "as camadas das rochas, especialmente onde estão as pinturas rupestres, também são facilmente visíveis e bem divididas, pois cada uma foi formada em um período diferente. $O$ intemperismo químico das rochas, ou seja, o processo de desmanche, também atua muito nessa região, com a ação do vento e das chuvas, e o intemperismo biológico, com o nascimento das plantas entre as rochas."

O autor da matéria destaca que os idealizadores da expedição almejam o desenvolvimento do turismo. Segundo o Miranda (2017) as famílias idealizadoras são representadas pelos senhores Cristóvão Feitosa, Manoel Rodrigues (seu Ginco), José Gonçalves, João Paulo Carneiro, tendo outros membros colaboradores. O objetivo é atrair turistas e agregar valor aos produtos e serviços locais, gerando renda e proporcionando qualidade de vida para as famílias da comunidade, além de proporcionar momentos de lazer aos visitantes e admiradores da natureza. Assim ele enfatizou a fala de um dos idealizadores:

É o que conta o produtor Cristovão Feitosa, 57 anos. "Desde o primeiro momento, me encantei com a beleza dessa região. Comecei então a visualizar que o lago, juntamente com as belezas do cerrado, poderia ser utilizado para o lazer, para a visitação turística. Logo, a ideia de criar um projeto assim, que trouxesse qualidade de vida, passou a ser para mim a maneira certa de usar isso a favor da população de Pilões" (MIRANDA, 2017, p.1).

\section{Ainda de acordo com a matéria}


No encontro foram debatidas entre os colaboradores ideias para explorar a potencialidade da comunidade Pilões, com estratégias de desenvolvimento sustentável para o ecoturismo, além de observar as questões geológicas, a fauna e flora, as maneiras de acesso aos pontos turísticos, locais de acampamento e registro fotográfico (MIRANDA, 2017, p.1),

Ele afirma também que,

No entorno de Pilões existem vários outros potenciais turísticos, como as praias do Rio Tocantins, ótimas para o banho, a pesca e outros esportes aquáticos. Há também uma cachoeira, mirantes naturais, passeio a cavalo, trilhas por meio do cerrado, além de poder desfrutar da culinária típica feita no fogão à lenha, tudo com muito amor e capricho (MIRANDA, 2017, p.1).

Também destaca a fala do morador, o qual tem em sua propriedade, uma área que pertence a Serra do Bandeira, é o caso do senhor Manuel Rodrigues. O jornalista afirma que:

É um dos idealizadores do projeto, e contou sua expectativa para a região. "Eu e meu amigo Cristóvão já tínhamos tentado há cinco anos formar um projeto de turismo, mas agora retornamos com novas ideias. Eu gosto muito de receber as pessoas aqui na minha terra. Quando cheguei na região, não tinha nada, só o povo morando. Eu vi esse lugar crescer, e sempre busquei trabalhar para a comunidade" (MIRANDA, 2017).

Miranda (2017), destacou também as entidades que compareceram a visitação. Segundo ele, o RURALTINS, foi o único órgão governamental que participou diretamente da expedição:

Carina Monte, formada em economia doméstica e Gyllhemberg Santiago, geógrafo, já realizam um trabalho de agroecologia no povoado Pilões. "É grande satisfação fazer parte do incentivo e apoio desse projeto, que venho acompanhando e assim perceber que como instituição de extensão rural, o órgão pode contribuir com ideias e estratégias, na tentativa de fortalecer o trabalho associado nas comunidades Ilha da Ema e Pilões", ressaltou a Carina (IBID).(MIRANDA, 2017 p.1)

Nesta perspectiva, na entrevista com os idealizadores do projeto, foi destacada a necessidade de um apoio institucional, "com cursos de capacitação para auxiliar a comunidade no projeto de ecoturismo". A prefeitura de Miracema foi indicada como possível parceira e o jornal Primeira Página buscou uma parceria com as prefeituras, secretarias de turismo e a comunidade local (MIRANDA, 2017). 
Terceiro momento, após a visitação constata-se até o momento algumas ações desenvolvidas na comunidade. Dentre elas a da fundação em outubro de 2017 a Associação Agroturística da Região dos Pilões e Ilha da Ema, AGROTUR. Tendo como presidente o Cristóvão Alves Feitosa e está há 2 anos na frente desta recente associação. Além disto, foi apresentado a Câmara Municipal de Vereadores o projeto de lei que considera essa associação como utilidade pública municipal e, em 17 de outubro de 2018, foi aprovado por unanimidade.

O momento ficou registrado no site da RURALTINS, Instituto de Desenvolvimento Rural do Estado Tocantins, ressalta a fala do Presidente na ocasião da aprovação do projeto: " $A$ Lei só se tornou possível com a contribuição da entidade estadual de fomento aos produtores do campo - RURALTINS. Hoje a gente fica muito feliz com a aprovação unanime da câmara, reconhecendo a nossa associação, facilitando a formação de mais parcerias e busca de recursos para desenvolver nossa região. A comunidade foi chamada a refletir sobre suas potencialidades e limitações" 2 .

Em linhas gerais, existe na comunidade o interesse e os que acreditam no potencial tem se manifestado a favor. Porém não se pode deixar de lado, os desafios encontrados até o dado momento, mesmo o local sendo hoje divulgado no site oficial da prefeitura em 2019, onde também coloca em destaque um novo empreendimento chega para região, uma pousada que foi construída a menos de dois anos, também divulgados enquanto ponto turístico na região ${ }^{3}$. Porém, mais que um processo de divulgação é necessário a infraestrutura, pois o local é distante da sede do município, sendo 43 quilômetros a serem percorridos, 27 deles em estradas não pavimentadas e necessita de uma cobrança de melhorias para o acesso ao local.

Por outro lado, um empresário tem acreditado no potencial daquele local, existe um grande empreendimento, uma pousada em que viu no local ponto ideal tem atraído turistas para conhecer o espaço construído e as belezas naturais presentes na região.

\section{Breves considerações}

O estudo apresentado teve como base em duas vertentes primeira pesquisa exploratória com objetivo de diagnosticar o potencial turístico na região dos Pilões no município de Miracema-TO. Mesmo instante também enquanto pesquisador participante do processo do andamento da pesquisa. Cuja teve como finalidade retratar a existência de um potencial turístico na comunidade, isso foi possível mediante a visitação que aconteceu em 09 de julho de 2017.

Inicialmente refletiu- se os conceitos de ecoturismo e do turismo retratando a fundamental importância desta prática turística que tem ganhado grandes proporções no contexto nacional. Segundo instante da pesquisa, foi a descrição para visitação a Serra do Bandeira, onde, o pesquisador também integrou-se ao grupo como também ele é morador e um dos idealizadores do turismo na Região dos Pilões e llha da Ema. Foram 11 pessoas, incluído 8 moradores um jornalista e dois representantes da Ruraltins participantes da expedição na Serra do Bandeira, o qual trilharam 5 quilômetros observando as belezas naturais daquele local, cujo a finalidade principal foi fazer o levantamento turístico daquele lugar. 
O levantamento ele foi discutido entre os participantes da visita à Serra do Bandeira saindo assim como breve produto uma matéria jornalística produzida pelo jornalista Rafael Miranda, presente também na expedição. Formada assim, por 11 pessoas, partiu para conhecer as belezas naturais culturais encontradas na Serra do Bandeira fica no pequeno povoado de Pilões, formado por 16 famílias de chacareiros espalhadas pela zona rural de Miracema. O povoado, que até então é ligado à agropecuária de subsistência, tenta aos poucos desenvolver o ecoturismo na região como forma de renda extra para a comunidade. Ao todo, são quatro horas de trilha para ir e voltar nas pinturas (MIRANDA, 2017).

Em seguida, ele contou os anseios moradores e todos envolvidos que desejam o desenvolvimento da prática do ecoturismo na comunidade dos Pilões. A matéria foi publicada na semana do dia 20 de julho de 2017, o então jornalista, Rafael Miranda, onde ele entrevistou os moradores e idealizadores que almejam a prática do ecoturismo e do turismo na região. A entrevista aconteceu logo após todos terem chegado da visitação, na tarde de 09 de julho de 2017.

Diante da experiência vivida onde foi possível fazer um breve diagnóstico a partir da expedição ocorrida, e da matéria jornalista produzida pelo integrante da visitação a Serra do Bandeira. É feito então esta reflexão, destacando esta importância do ato de se planejar para se pensar de como desenvolver uma atividade turística em uma local. É necessário, então, segundo Ruschmann (1999) a caracterização geral do ambiente, onde é realizado o levantamento dos aspectos gerais, geográficos, econômicos e sociais da região do estudo. Inventário turístico, sendo o diagnóstico das condições naturais, culturais bem como a infraestrutura turística, recursos humanos para o turismo e caracterização da demanda.

Portanto é diante deste diagnóstico inicial que estão sendo desencadeadas outras ações após a iniciativa promovida pelos moradores e idealizadores, o qual por meio do diagnóstico feito. Houve a necessidade de se organizarmos, para isso fundou- se associação na comunidade. Associação Agroturística dos Pilões e llha da Ema, representado pelo seu Cristóvão Alves Feitosa, ela existe há quase dois anos, porém temos encontrado muitas dificuldades, dentre elas a resistência dos moradores em associa- lá, para isso temos trabalhado com importância do associativismo para podermos cobrar o poder público mais consistência para de fato a comunidade seja atendida.

Atualmente o pesquisador participa como voluntário encontra-se pouco ausente devido estar buscando aperfeiçoamento e no próximo ano deseja está mais presente nas reuniões que acontece todo primeiro domingo de cada mês na cada de um associado.

Contudo, ela existe há quase dois anos, porém temos encontrado muitas dificuldades, dentre elas a resistência dos moradores em associa- lá, para isso temos trabalhado com importância do associativismo para podermos cobrar o poder público mais consistência para de fato a comunidade seja atendida.

\section{Referências Bibliográficas}

BACCHI, R.; QUEIROZ; O.T.M.M.; NEIMAN, Z. A Educação Ambiental no Ecoturismo e no Turismo de Aventura: estudo de caso do Parque Estadual da Serra do Mar, Núcleo Santa Virgínia (SP). Revista Brasileira de Ecoturismo, São Paulo, v.10, n. 2, maio/jul. 2017, p. 498-524. 
BARRETO, M.V. Planejamento e organização em turismo. Campinas: Papirus, 1991.

BENFÍRE, P.W.; CASTRO, C.T.; SILVA, M.V.; GALVÃO, P.L.; COSTA, S.P. Planejamento turístico: aspectos teóricos e conceituais e suas relações com o conceito de turismo, Revista Turismo Contemporâneo, v.4, 15 abr, 2016.

BRASIL. Ministério do Meio Ambiente. Diretoria de Educação Ambiental; Ministério da Educação. Coordenação Geral de Educação Ambiental. Programa Nacional de Educação Ambiental - ProNEA. 3. ed. Brasília, DF: Edições MMA, 2005. 102 p.

BENI, M.C. Política e estratégia do desenvolvimento regional: planejamento integrado e sustentável do turismo. Turismo em Análise, São Paulo, n. 1, mai. p.717, 1999.

BUENO, F.P.; PIRES, P.S. Ecoturismo e educação ambiental: possibilidades e potencialidades de conservação da natureza. Seminário De Pesquisa Em Turismo Do Mercosul 4., 2006, Caxias do Sul, RS. Anais... Caxias do Sul: Universidade de Caxias do Sul, 2006. Disponível em: https://www.ucs.br/ucs/tplSemMenus leventos/seminarios semintur/semin tur 4/arquivos 4 seminario/GT08-5.pdf.

Acesso em 04.Nov.2019.

FONSECA, J.J.S. Metodologia da Pesquisa Cientifica, UECE, 2002 127p.Disponível: em: <http://www.ia.ufrri.br/ppgea/conteudo/conteudo-2012-1/1SF/Sandra/apostila Metodologia.pdf>. Acesso em 27 jun.2019.

MIRANDA, Rafael, Pinturas rupestres em Miracema-TO: um tesouro ainda pouco explorado. Disponível em: <http://www.primeirapagina.to/noticias/pinturas-rupestresem-miracema-um-tesouro-ainda-pouco-explorado/>.Acesso em 27 jun.2019.

PIRES, P.S. A dimensão conceitual do ecoturismo. Turismo: visão e ação. Itajaí, v. 1, n. 1, p.75-92, jan./jun.1998.

RUSCHMANN, D.V.M. Planejamento Turístico. In ANSARAH, M.G.R. (org.). Turismo. Como aprender, como ensinar. São Paulo: Senac. v.2, 4. ed. 2001.

RABELO, D.L. O Ecoturismo como experiência e prática de liberdade. Revista Brasileira de Ecoturismo, São Paulo, v. 3, n. 1, jan. p.11-22, 2010.

THIOLENT, M. Metodologia da pesquisa-ação: São Paulo: Cortez, 13.ed 2004. $107 p$.

\section{Notas:}

'Matéria completa sobre a expedição, que aconteceu em 11/07/2017 o qual o jornalista dar ênfase nos potenciais turístico existentes na região dos Pilões, em especial no local visitado, a Serra do Bandeira residente dentro de várias propriedades rural na região. Disponível em: $<$ http://primeirapagina.to/noticias/pinturas-rupestres-em-miracema-um-tesouro-aindapouco-explorado/> Acesso em 27/jun/2019.

2 Informações sobre o dia da aprovação do projeto que aconteceu em 17 de outubro na câmara municipal de Miracema do Tocantins, com a presença dos representantes da Ruraltins na ocasião. Disponível em $<$ https://ruraltins.to.gov.br/noticia/2018/10/17/projeto-de-lei-incentiva-associacaoagroturistica-na-regiao-de-miracema/> em 27/06/2019. 
${ }^{3}$ A região dos Pilões integrou-se ao pontos turísticos do município em 2019, como consta em seu site oficial disponível em: <https://miracema.to.gov.br/cidade/pontosturisticos>. Acesso em 27/.jun.2019.

João Paulo Carneiro dos Reis: Universidade Federal do Tocantins, Porto Nacional, TO, Brasil.

E-mail: joao92geo@gmail.com

Link para o currículo Lattes: http://lattes.cnpq.br/4575046970052301

Rosane Balsan: Universidade Federal do Tocantins, Porto Nacional, TO, Brasil.

E-mail: rosanebalsan@hotmail.com

Link para o currículo Lattes: http://lattes.cnpq.br/1521061622984234

Sandra de Oliveira Gomes Pereira: Universidade Federal do Tocantins, Porto Nacional, TO, Brasil.

E-mail: sandra82gomes@gmail.com

Link para o currículo Lattes: http://lattes.cnpq.br/61557612552449

Data de submissão: 24 de março de 2019

Data de recebimento de correções: 25 de março de 2019

Data do aceite: 25 de março de 2019

Avaliado anonimamente 